Hamed Ramezani ${ }^{1}$, Seyed Naser Azizi ${ }^{1, \star}$ and Giancarlo Cravotto ${ }^{2}$

\title{
Improved removal of methylene blue on modified hierarchical zeolite Y: Achieved by a "destructive-constructive" method
}

https://doi.org/10.1515/gps-2019-0043

Received October 31, 2018; accepted May 16, 2019.

Abstract: In this study removal of methylene blue (MB) from an aqueous solution by zeolite (NaY) and related modified hierarchical zeolite (MY) has been investigated. The NaY zeolite with a low ratio of $\mathrm{Si} / \mathrm{Al}$ was synthesized from silica extracted rice husk ash. It was transformed to hierarchical zeolite (MY) by a "destructive-constructive" modification method using tetramethyl ammonium hydroxide (TMAOH) and a cationic surfactant (Cetyltrimethylammonium bromide, CTAB) as a templating agent. Various characterization method like FT-IR, XRF, XRD, BET, TGA, SEM and BJH confirmed the construction of parent zeolite and also successfulness of the modification process. EDX showed a negligible change of Si/Al ratio during modification which is favorite in adsorption of cationic MB dye. In order to study the interaction between the surface of adsorbent and adsorbate, six common isotherms were used. By Langmuir isotherm, it is clarified that, the maximum adsorption capacity $\left(\mathrm{q}_{\mathrm{m}}\right)$ had improvement from $15.2 \mathrm{mg} \mathrm{g}^{-1}$ to $133.1 \mathrm{mg} \mathrm{g}^{-1}$ for $\mathrm{NaY}$ and MY, respectively. The kinetic studies showed that the adsorption obeys the Pseudo-second order model for both $\mathrm{NaY}$ and MY zeolites. Also, the usage frequency of the MY was investigated. Results showed that there was not any noticeable change in performance of adsorption after four circles.

Keywords: zeolite NaY; hierarchical zeolite; methylene blue; destructive-constructive method; adsorption

\footnotetext{
* Corresponding author: Seyed Naser Azizi, Analytical Division, Faculty of Chemistry, University of Mazandaran, 47416-95447 Babolsar, Iran, Tel.: +981135342350, Fax: +981135342380, e-mail: azizi@umz.ac.ir

Hamed Ramezani, Analytical Division, Faculty of Chemistry, University of Mazandaran, 47416-95447 Babolsar, Iran Giancarlo Cravotto, Dipartimento di Scienza e Tecnologia del Farmaco, University of Turin, Via P. Giuria 9, I-10125 Turin, Italy
}

\section{Introduction}

Development of urbanization and industrialization lead to the release of high amounts of wastes into the environment. In addition, drought is spreading in the most area of the world. Therefore wastewater treatment can be a vital issue that nowadays humanity encounter [1]. The presence of dyes in water, even in less than $1 \mathrm{ppm}$, are strongly observable and also undesirable. They prevent penetration of sunlight into the water, resulting annihilating the aquatic biota health problems such as mutagenic and carcinogenic effects [2,3]. Furthermore, by reducing the oxygen levels in water, suffocation of aquatic flora will happen [2-4]. Methylene blue (MB) belongs to basic dyes which are water-soluble cationic dyes that are mainly applied for dying acrylic fibers, wool, silk and cotton [4]. Adsorption is an effective method for water treatment and has a high potential for the removal and recovery of dyes from wastewater. Initial cost, the simplicity of design and ease of operation made it a premier method for purification of water [4]. The most common adsorbent for these purposes is activated carbon [3-5]. However, it suffers from the high cost of production. Also, its regeneration is an inconvenient process $[5,6]$.

Zeolites are aluminosilicates porous materials with a three-dimensional framework. It consists of $\mathrm{SiO}_{4}$ and $\mathrm{AlO}_{4}$ tetrahedra as the primary units, which oxygen atom connects these two units [7]. The presence of Al species in the framework of zeolites induce negative charges that compensate by extra framework cations like $\mathrm{Na}^{+}$which is mobile and easily exchangeable by other cations. Based on the number of tetrahedra, there are different pores with different sizes: 8 tetrahedra with small pore size of 0.30-0.45 nm (e.g., zeolite A), 10 tetrahedra with medium pore size of 0.45-0.60 nm (e.g., ZSM - 5), 12 tetrahedra with large pore size of 0.6-0.8 nm (e.g., zeolites Y) and more than 14 tetrahedra extra-large pores (e.g., UTD - 1). These size dependence channels allow capture of molecules in different sizes. In addition, the geometry and morphology of the zeolites channels allow shape-selective adsorption and catalysis on zeolites [6]. The adsorption properties of the zeolites are controllable and depend on $\mathrm{Si} / \mathrm{Al}$ ratio, 
they vary from hydrophobic to hydrophilic type materials [8]. By increasing the $\mathrm{Si} / \mathrm{Al}$ ratio, the hydrophilicity of zeolite will decrease. The low silica zeolites are aluminum saturated and possess the higher cations concentrations to compensate negative charge induced by inserting the $\mathrm{Al}$ in the frameworks. Therefore, they give optimum adsorption properties towards cations and organic molecules with hydrophilic nature [9].

Porous materials based on their pore diameter (d) put into three categories: microporous, $\mathrm{d}<2.0 \mathrm{~nm}$; mesoporous, $d=2.0-50 \mathrm{~nm}$; macroporous, $d>50 \mathrm{~nm}$ [8]. There are lots of molecules with the size higher than zeolite pores. It has been proven that the introduction of mesopores within microporous zeolite structures facilitate mass transfer to active sites in zeolites [10,11]. The presence of only micropores in the structure of zeolite cause mass transfer limitations. Pore engineering is a way to improve the accessibility of the zeolites pores. As mentioned before, insertion pores with sizes in the range of mesopores in the presence of microspores in the zeolites which is referred to hierarchical zeolites, could enhance the diffusion path length several order of magnitude faster than in the presence of micropores solely. The creation of mesopores in zeolite crystals is equivalent to increasing the external surface area of the zeolite, result in easier diffusion of larger molecules in zeolite [8,12].

Generally, there are two main strategies in the synthesis of hierarchical zeolites: direct synthesis and post-synthesis; also named as "bottom-up" and "topdown" approaches, respectively [13]. Direct synthesis is a constructive method in which the mesoporosity will be formed along with synthesizing the zeolite by employing soft or hard templates [13]. The usual methods for postsynthesis consist of desilication, dealumination, high temperature steaming and acid leaching. All of these destructive methods are based on creating a defect in the structure of parent zeolite. The mesoporosity will form accidentally and therefore arbitrary mesoporous forms which mainly have located in internal cavities and are inaccessible [10]. Wang et al. and Ying and Garcia-Martinez were the first researchers who utilized the recrystallization of the zeolites in basic media and in the presence of a surfactant as a mesopore directing agent $[14,15]$. This method which is referred to "destructive-constructive" approach is based on partial demolition and dissolution of the parent zeolite structure by a base like $\mathrm{NaOH}, \mathrm{TMAOH}$, $\mathrm{Na}_{2} \mathrm{CO}_{3}, \mathrm{NH}_{4} \mathrm{OH}$, etc. and then recrystallization of them in the presence of a cationic surfactant (usually CTAB) as a mesoporous template. This method allowed inserting tailored mesopores simultaneously original micropores in zeolites structures rather than uncontrollable and random non-optimized mesoporosity in other post-synthesis methods.

Zeolite NaY belongs to the faujasite family of zeolites. Its high surface area and relatively large pores, $(0.74 \mathrm{~nm})$, low cost, excellent thermal and hydrothermal stability made it a versatile compound in adsorption and catalysis [9]. Despite its exemplary characteristics, zeolite $\mathrm{NaY}$, because of microporous character, like other zeolites, suffer from diffusion problems for bulky molecules. As mentioned above inserting a secondary mesopore $(2-50 \mathrm{~nm})$ in addition to the micropores will resolve this deficiency. In this work the zeolite $\mathrm{NaY}$ was synthesized by the low cost silica extracted rice husk ash as the silica source. The prepared zeolite carried out the low ratio of $\mathrm{Si} / \mathrm{Al}$ and therefore had hydrophilic features in comparison with available commercial one, so it was proper for removal of cationic dyes like methylene blue. In order to improve the adsorption process of the bulky methylene blue molecule $(1.42 \times 0.611 \mathrm{~nm})$, the presence of micropores $(\sim 1.4 \mathrm{~nm})$ solely were not satisfying therefore with a "destructive-constructive" method, as-synthesized zeolite was modified and hierarchical zeolite (MY) was achieved which possessed higher external surface area. The results showed that this hierarchical zeolite MY had improved adsorption capacity in the removal of methylene blue in comparison with parent $\mathrm{NaY}$ zeolite.

\section{Experimental}

\subsection{Material and instruments}

Hydrochloric acid (37\%), sodium hydroxide (98\%) and methylene blue were all purchased from Merck. Sodium aluminate was supplied from VWR. Amorphous silica which is one of the raw materials in the synthesis of zeolite $\mathrm{NaY}$, was extracted from rice husk ash and its composition was determined by XRF (about 84\% (w/w)). TMAOH 20\% and CTAB were prepared from Sigma-Aldrich.

\subsection{Apparatus}

The elemental composition of the extracted silica was determined by X-ray fluorescence spectrometry (XRF, PHILIPS, model PW 1480). In order to confirm the structure and crystallinity of as-prepared zeolite, an advance Bruker D8 XRD using $\mathrm{Cu}$ K $\alpha$ radiation $(\lambda=0.15406 \mathrm{~nm})$ was used. The Low angle XRD pattern was achieved by a Panalytical model X' Pert PRO MPD, Netherlands. The 
FT-IR spectrum of zeolite was recorded by Bruker Vector 22, Germany. In order to determination of the surface area and porosity, a BET (Quantachrom Nova series) was also used. Thermogravimetric analyzer from Perkin Elmer model TGA 4000 was used for recording the TGA thermogram. The UV-vis spectrophotometer which was utilized for determination of the concentration of $\mathrm{MB}$ after adsorption was from Pg instruments, model T90, and an 827 model of Metrohm $\mathrm{pH}$ meter was used for measuring the $\mathrm{pH}$ of the initial adsorption solution. For investigation of the reusability performance of adsorbent a microwave furnace (Microsynth MILESTONE) has been utilized to calcinate the methylene blue adsorbed onto surface of zeolite.

\subsection{Synthesis of hierarchical zeolite from silica extracted rice husk ash}

At the first step, the silica was extracted from rice husk ash according to Kalapathy method [16]. The analysis of the extracted powder by XRF showed $84.25 \% \mathrm{SiO}_{2}$ was achieved. Then this value was used for the synthesis of zeolite NaY based on a two-steps seeding technique [7]. Briefly, two types of gels named as seed gel and feed stuck gel were prepared according to molar ratios of $10.67 \mathrm{Na}_{2} \mathrm{O}$ : $\mathrm{Al}_{2} \mathrm{O}_{3}: 10 \mathrm{SiO}_{2}: 180 \mathrm{H}_{2} \mathrm{O}$ and $4.30 \mathrm{Na}_{2} \mathrm{O}: \mathrm{Al}_{2} \mathrm{O}_{3}: 10 \mathrm{SiO}_{2}$ : $180 \mathrm{H}_{2} \mathrm{O}$, respectively. The seed gel was aged for $24 \mathrm{~h}$ and then slowly added to feed stuck gel which prepared and used immediately without aging. The final gel possessed $5 \%$ (mol) of the seed gel, resulted in overall gel with a molar ratio of $4.62 \mathrm{Na}_{2} \mathrm{O}: \mathrm{Al}_{2} \mathrm{O}_{3}: 10 \mathrm{SiO}_{2}: 180 \mathrm{H}_{2} \mathrm{O}$. This overall gel also was aged for $24 \mathrm{~h}$ and then transferred into a Teflon-lined stainless steel autoclave and was crystallized at $90^{\circ} \mathrm{C}$ for $24 \mathrm{~h}$ in order to achieve the crystalline zeolite $\mathrm{NaY}$. Converting the NaY zeolite based on "destructiveconstructive" method was according to a procedure that was used by Chal and García-Martínez [17,18]. At first step in order to reach the zeolite $\mathrm{HY}$ from zeolite $\mathrm{NaY}, 1.0 \mathrm{~g}$ of parent zeolite was stirred in $1 \mathrm{M}$ ammonium chloride solution at $80^{\circ} \mathrm{C}$ for $4 \mathrm{~h}$ and then washed three times with double distilled water to remove chloride ion. Then the resulted $\mathrm{NH}_{4} \mathrm{Y}$ zeolite was calcinated in a muffle furnace for $5 \mathrm{~h}$. The achieved HY was dispersed and stirred for $30 \mathrm{~min}$ in $30 \mathrm{~mL}$ 0.09 M tetramethyl ammonium hydroxide (TMAOH 25\% in water) and $0.5 \mathrm{~g}$ hexadecyltrimethylammonium bromide (CTAB). The aforementioned solution was transferred to a Teflon-lined stainless steel autoclave and put in an oven at $150^{\circ} \mathrm{C}$ for $20 \mathrm{~h}$. Finally, the product was washed with double distilled water and dried overnight at $80^{\circ} \mathrm{C}$. Eventually the organic components were eliminated by calcination at $550^{\circ} \mathrm{C}$ for $8 \mathrm{~h}$.

\subsection{Adsorption experiments}

\subsubsection{Isotherm study}

In order to study of the adsorption isotherm, $10 \mathrm{~mL}$ of $\mathrm{MB}$ solutions with concentrations in the range of 10-100 ppm for $\mathrm{NaY}$ and 10-350 ppm for MY were shaken in the presence of $0.02 \mathrm{~g}$ of each adsorbents for $1 \mathrm{~h}$. After centrifuge, the residual dye concentrations were determined by spectrophotometer at $664 \mathrm{~nm}$ and using a standard calibration curve. In order to calculate the adsorption capacity $\left(q_{e}\right)$, the following equation was utilized:

$$
q_{e}=\frac{\left(C_{0}-C_{e}\right)}{m} \times V
$$

where $\mathrm{C}_{0}$ and $\mathrm{C}_{\mathrm{e}}$ are the initial and equilibrium concentrations of solutions $(\mathrm{mg} / \mathrm{L})$, respectively and $\mathrm{m}(\mathrm{g})$ is the amount of adsorbent, V (L) is the volume of the solution. Therefore the adsorption capacity $\left(q_{e}\right)$ was achieved in $\mathrm{mg} / \mathrm{g}$.

Then $\mathrm{q}_{\mathrm{e}}$ versus $\mathrm{C}_{\mathrm{e}}$ was plotted and assessed by various isotherm equations inserted in Table 1. An Origin 8.6 software was used for nonlinear curve fitting by exploiting these equations.

\subsubsection{Kinetic study}

In order to determine the kinetic parameters of the adsorption process, $0.01 \mathrm{~g}$ of $\mathrm{NaY}$ and $0.01 \mathrm{~g}$ of $\mathrm{MY}$ were added to $25 \mathrm{~mL}$ of 10 and $20 \mathrm{ppm}$ solutions of $\mathrm{MB}$, respectively. Each solution was stirred in different time intervals until $180 \mathrm{~min}$. Then the adsorption capacity vs. time was plotted. Two kinetic models, Pseudo first order or Lagergren and Pseudo-second order were used in order to evaluate the kinetic. The equation for Pseudo first order model is as follow:

$$
q_{t}=q_{e}\left(1-\exp \left(-k_{1} t\right)\right)
$$

where $\mathrm{q}_{\mathrm{t}}$ and $\mathrm{q}_{\mathrm{e}}$ are the adsorption capacity at time $\mathrm{t}$ and in equilibrium, $\mathrm{k}_{1}$ is the adsorption rate constant. The Pseudo second order can be illustrated as Eq. 3:

$$
q_{t}=\frac{k_{2} t q_{e}^{2}}{1+k_{2} q_{e} t}
$$

where $q_{t}$ and $q_{e}$ are the same as Pseudo- first order parameters and $\mathrm{k}_{2}$ is the rate constant of pseudo- second order. In order to curve fitting purposes, the Origin software was used. 
Table 1: Non-linear models of adsorption isotherms and their parameter.

\begin{tabular}{|c|c|c|}
\hline Isotherm & Formula & Parameter \\
\hline Langmuir & $q_{e}=\frac{q_{m} k_{L} C_{e}}{1+k_{L} C_{e}}$ & $\begin{array}{l}\mathrm{q}_{\mathrm{e}} \text { : amount of } \mathrm{MB} \text { adsorbed onto per } \\
\text { unit mass of zeolite }\left(\mathrm{mg} \mathrm{g}^{-1}\right) \\
\mathrm{q}_{\mathrm{m}}: \text { the monolayer or maximum } \\
\text { adsorption capacity }\left(\mathrm{mg} \mathrm{g}^{-1}\right) \\
\mathrm{C}_{\mathrm{e}} \text { : the equilibrium concentration } \\
\left(\mathrm{mg} \mathrm{L}^{-1}\right) \\
\mathrm{K}_{\mathrm{L}} \text { : affinity of the binding sites and } \\
\text { energy of adsorption }\left(\mathrm{mg}^{-1}\right)\end{array}$ \\
\hline Freundlich & $q_{e}=k_{F} C_{e}^{1 / n}$ & $\begin{array}{l}\mathrm{q}_{\mathrm{e}} \text { : amount of } M B \text { adsorbed at } \\
\text { equilibrium }\left(\mathrm{mg} \mathrm{g}^{-1}\right) \\
\mathrm{C}_{\mathrm{e}} \text { : the equilibrium concentration } \\
\left(\mathrm{mg} \mathrm{L}^{-1}\right) \\
\mathrm{K}_{\mathrm{F}} \text {, related to the adsorption capacity } \\
\mathrm{n} \text { : related to adsorption intensity of } \\
\text { the sorbent }\end{array}$ \\
\hline $\begin{array}{l}\text { Redlich- } \\
\text { Peterson }\end{array}$ & $q_{e}=\frac{A C_{e}}{1+B C_{e}^{g}}$ & $\begin{array}{l}\mathrm{q}_{\mathrm{e}} \text { : amount of } \mathrm{MB} \text { adsorbed at } \\
\text { equilibrium }\left(\mathrm{mg} \mathrm{g}^{-1}\right) \\
\mathrm{C}_{\mathrm{e}} \text { : the equilibrium concentration } \\
\left(\mathrm{mg} \mathrm{L}^{-1}\right) \\
\mathrm{A}, \mathrm{B} \text { and } \mathrm{g} \text { are the Redlich-Peterson } \\
\text { parameters }\end{array}$ \\
\hline Temkin & $q_{e}=A+B \ln C_{e}$ & $\begin{array}{l}\mathrm{q}_{\mathrm{e}} \text { : amount of } \mathrm{MB} \text { adsorbed at } \\
\text { equilibrium }\left(\mathrm{mg} \mathrm{g}^{-1}\right) \\
\mathrm{C}_{\mathrm{e}}: \text { the equilibrium concentration } \\
\left(\mathrm{mg} \mathrm{L}^{-1}\right) \\
\mathrm{A}, \mathrm{B} \text { and } \mathrm{g} \text { are the Temkin parameters }\end{array}$ \\
\hline $\begin{array}{l}\text { Koble- } \\
\text { Corrigan }\end{array}$ & $q_{e}=\frac{A C_{e}^{n}}{1+B C_{e}^{n}}$ & $\begin{array}{l}\mathrm{q}_{\mathrm{e}} \text { : amount of } \mathrm{MB} \text { adsorbed at } \\
\text { equilibrium }\left(\mathrm{mg} \mathrm{g}^{-1}\right) \\
\mathrm{C}_{\mathrm{e}} \text { : the equilibrium concentration } \\
\left(\mathrm{mg} \mathrm{L}^{-1}\right) \\
\mathrm{A}, \mathrm{B} \text { and } \mathrm{n} \text { are the Koble-Corrigan } \\
\text { parameters }\end{array}$ \\
\hline Toth & $q_{e}=\frac{k_{T} C_{e}}{\left(a_{T}+C_{e}\right)^{1 / t}}$ & $\begin{array}{l}\mathrm{q}_{\mathrm{e}}: \text { the adsorbed amount at } \\
\text { equilibrium }\left(\mathrm{mg} \mathrm{g}^{-1}\right) \\
\mathrm{C}_{\mathrm{e}}: \text { the adsorbate equilibrium } \\
\text { concentration }\left(\mathrm{mgL}^{-1}\right) \\
\mathrm{a}_{\mathrm{T}}: \text { Toth isotherm constant }(\mathrm{L} / \mathrm{mg}) \\
\mathrm{t}: \text { Toth isotherm constant } \\
\mathrm{K}_{\mathrm{T}}: \text { Toth isotherm constant }(\mathrm{mg} / \mathrm{g})\end{array}$ \\
\hline
\end{tabular}

\section{Results and discussion}

\subsection{Characterization of adsorbents}

Figure 1 shows the FT-IR spectra of the microporous $\mathrm{NaY}$ and hierarchical MY. There are two categories of characteristic vibration patterns for zeolite $\mathrm{NaY}$ which are related to internal and external tetrahedra. The internal tetrahedra included asymmetric and symmetric stretching modes in 1250-920 $\mathrm{cm}^{-1}$ and $720-650 \mathrm{~cm}^{-1}$ and $\mathrm{T}-\mathrm{O}(\mathrm{T}=\mathrm{Si}$ or $\mathrm{Al}$ ) bending vibration at $500-420 \mathrm{~cm}^{-1}$. The vibration

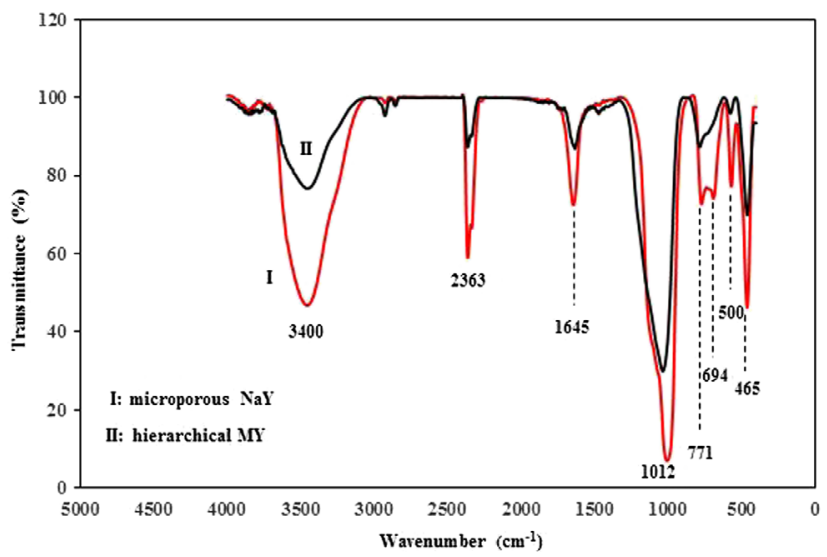

Figure 1: FT-IR spectra of (I) microporous $\mathrm{NaY}$ and (II) hierarchical MY.

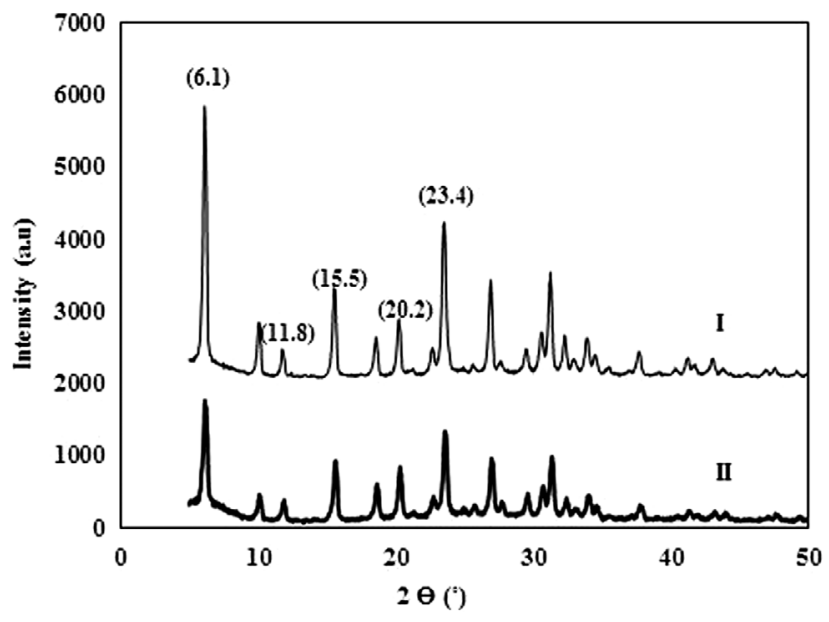

Figure 2: Wide angle XRD patterns of (I) microporous $\mathrm{NaY}$ and (II) hierarchical MY.

related to external linkages consist of asymmetrical and symmetrical stretching modes at $1150-1050 \mathrm{~cm}^{-1}$ and $820-750 \mathrm{~cm}^{-1}$ and double ring vibration at $650-500 \mathrm{~cm}^{-1}$. The above mentioned vibration pattern are assigned in Figure 1. It is seen, after inserting the mesopores, approximately all vibration pattern of zeolite $\mathrm{NaY}$ has maintained and only the peak at $694 \mathrm{~cm}^{-1}$ has changed which is related to internal tetrahedra symmetric stretching modes and therefore a confirmation of the structure alteration of the zeolite crystals. Broad band at around $3400 \mathrm{~cm}^{-1}$ is assigned to $\mathrm{OH}$ vibration of adsorbed $\mathrm{H}_{2} \mathrm{O}$. The decrease of its intensity in hierarchical MY is observed which is related to desorption of the proposed water in calcination step during the preparation of hierarchical MY (Section 2.3).

In Figure 2 the wide angle diffractogram could be seen for both parent microporous $\mathrm{NaY}$ and hierarchical MY. As can be observed the characteristic peaks at $2 \theta$ $6.1^{\circ}, 11.8^{\circ}, 15.5^{\circ}, 20.2^{\circ}$ and $23.4^{\circ}$ related to a NaY zeolite has maintained after modification to hierarchical MY but 


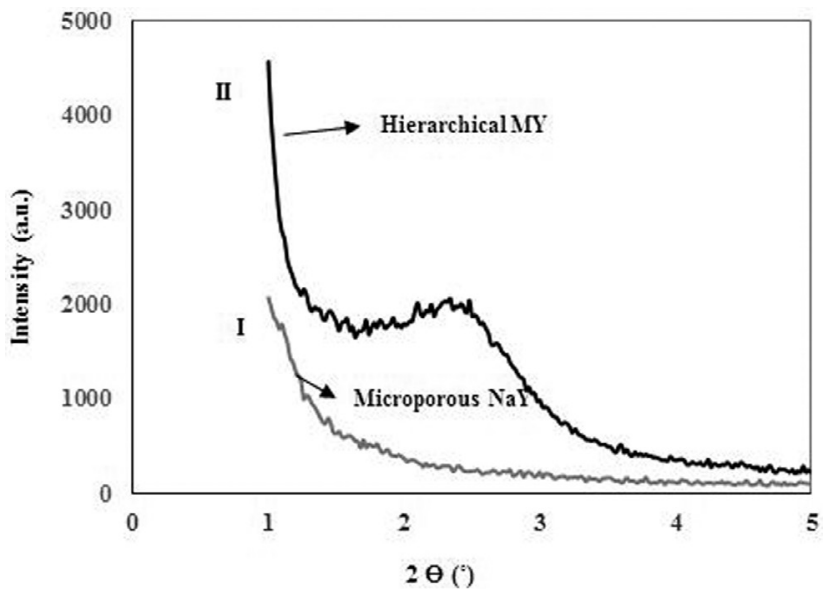

Figure 3: Low angle XRD pattern for (I) microporous $\mathrm{NaY}$ and (II) hierarchical MY.
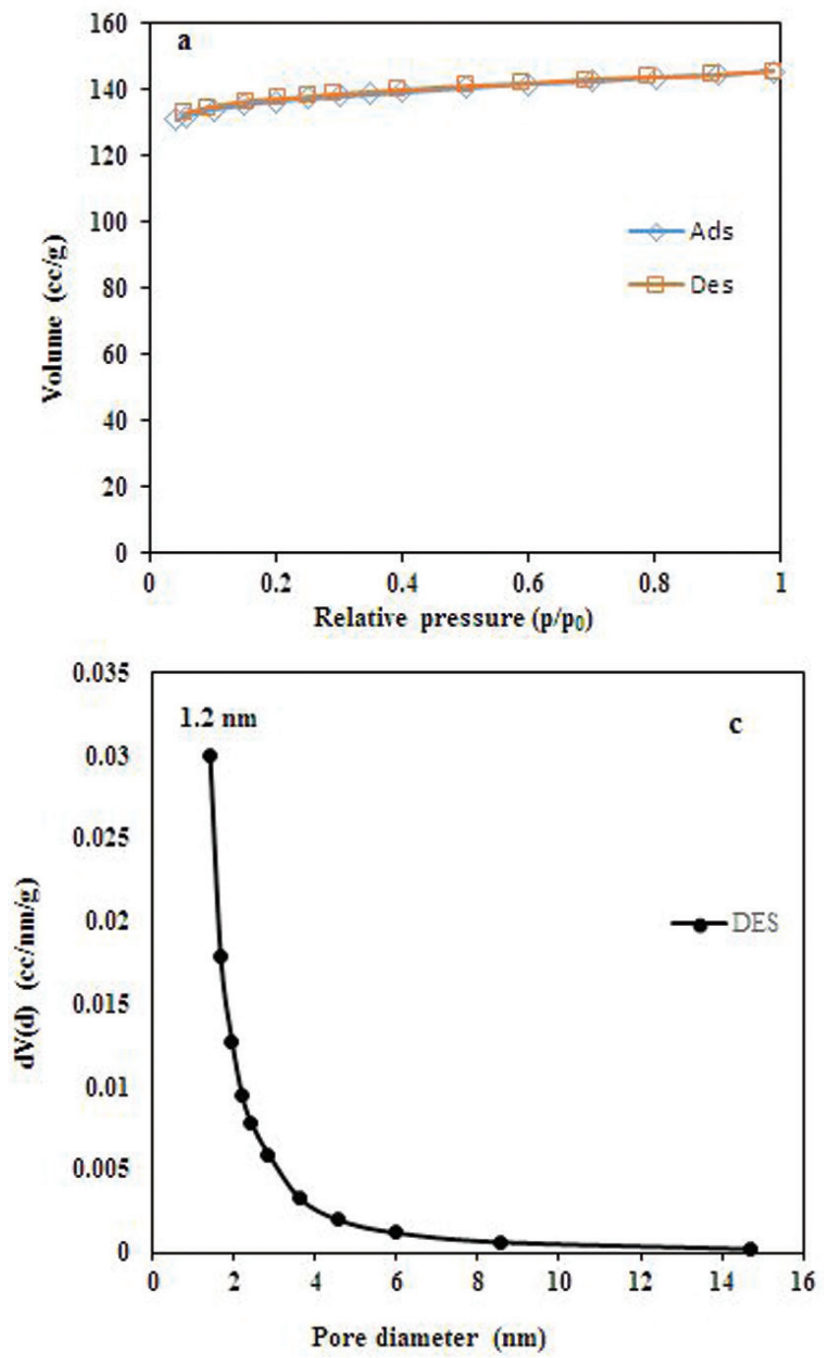

because of partially destructions of parent microporous $\mathrm{NaY}$ crystals, which are in charge of the zeolite XRD patterns, and formation of mesoporosity, the intensities of hierarchical MY peaks have been diminished [7,19].

The low angle XRD of the both zeolites has been inserted in Figure 3. It is seen that there is no peak at $2 \theta$ of $0.8-5$ for parent $\mathrm{NaY}$. In the case of hierarchical MY adsorbent, a peak at $2 \theta$ around $2.4^{\circ}$ can be seen which implies that the ordered mesoporous pores has been constructed and confirm the successfulness of the "destructive-constructive" modification method in formation of ordered and tailored mesopores. This phenomenon is observed when the template is used to construct of the ordered mesopores [17].

Investigation of the $\mathrm{N}_{2}$ adsorption-desorption isotherms of the proposed adsorbents is a reliable method
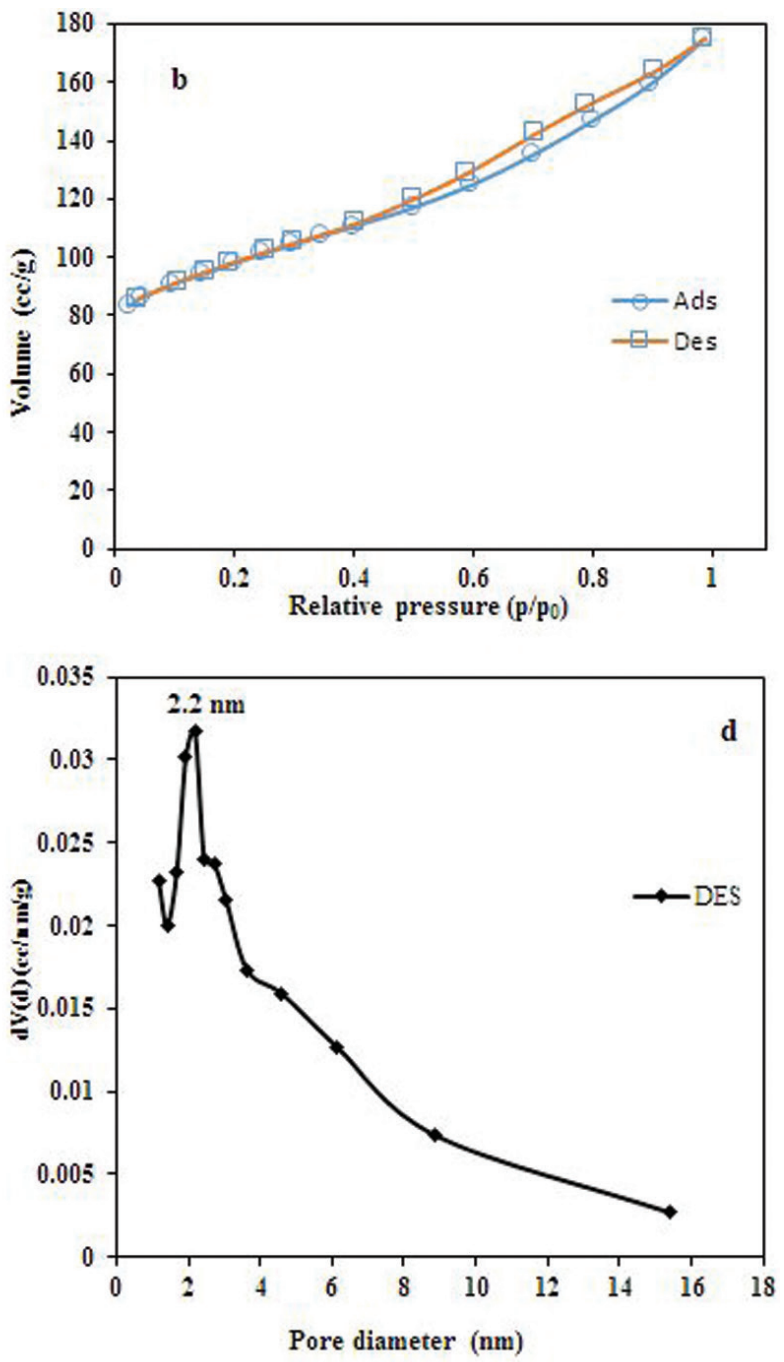

Figure 4: $\mathrm{N}_{2}$ adsorption-desorption isotherm plots of (a) microporous $\mathrm{NaY}$ (b) hierarchical MY and pore size distribution of the (c) microporous $\mathrm{NaY}$, (d) hierarchical MY. 
in discriminations between micro and mesopores systems. In Figures $4 \mathrm{a}$ and $4 \mathrm{~b}$, the isotherms of both parent and modified hierarchical zeolites have been inserted. The horizontal plateau until high relative pressure without any hysteresis is related to a type I isotherm which is the intrinsic characteristic of the materials with the only micropores (Figure 4a) [20]. After modification of as-synthesized zeolite and inserting some typical mesopores, the horizontal plateau with the upward procedure at higher relative pressure could be seen (Figure 4b). This positive slope, instead of the only horizontal saturation plateau along the whole region of isotherm, implies the significant presence of mesoporosity [20]. This order which is a combination of Isotherms I and IV is indicative of a bimodal micropoures and mesopores systems [21]. Appearing the hysteresis loop in the isotherm also confirms the presence of mesopores. The horizontal hysteresis loop which is observed in the Figure $4 \mathrm{~b}$ could be related to the formation of ink bottle type mesopores. From the t-plot method, the internal surface area was determined and therefore by considering the total surface area achieved by BET method it was clarified that, the external surface area of $32.823 \mathrm{~m}^{2} / \mathrm{g}$ for microporous $\mathrm{NaY}$ has changed to $137.730 \mathrm{~m}^{2} / \mathrm{g}$ for hierarchical MY. This remarkable growth in external surface area also confirms the formation of the mesopores in the microporous zeolite crystals [12].

Pore size distribution profiles of the $\mathrm{NaY}$ and MY are observed in Figures 4c and 4d. By the BJH method and using desorption branch of the nitrogen isotherm, the pore size distribution and the adsorbed volume was calculated. The pore size in the range of only $1.2 \mathrm{~nm}$ for microporous $\mathrm{NaY}$ could be seen in Figure 4c. In Figure 4d, the BJH of hierarchical MY zeolite is depicted. The presence of a variety of pore size distributions is the manifest of the hierarchical zeolites. As can be seen, there are pore size in the ranges of 1.2 to $6 \mathrm{~nm}$ in which the pores size of $2.2 \mathrm{~nm}$ are in maximum abundance. The procedure observed in the $\mathrm{BJH}$ method is completely in agreement with the data achieved by the BET methods. In Table 2 the textural properties of both microporous $\mathrm{NaY}$ and hierarchical MY is inserted.

In Figure 5 the SEM and EDX results of the zeolites has been depicted. The SEM micrograph shows that the synthesized zeolites NaY has well-shaped crystals (Figure 5a). In Figure 5b, which is related to hierarchical MY, it is obvious that, after the modification process no alteration in crystal shape and habit has happened. The EDX analysis of microporous NaY and hierarchical MY (Figures $5 \mathrm{c}$ and $5 \mathrm{~d}$ ) corroborates the values of $\mathrm{Si} / \mathrm{Al}$ ratio for both zeolites are the same and is nearly 2 . These results show that during conversion of microporous $\mathrm{NaY}$ to hierarchical MY by the proposed "destructive-
Table 2: Surface area and pore volume properties of microporous $\mathrm{NaY}$ and related hierarchical MY.

\begin{tabular}{lccccc}
\hline Adsorbents & $\begin{array}{c}\text { Total } \\
\text { surface } \\
\text { area } \\
\left(\mathrm{m}^{2} \mathbf{g}^{-1}\right)^{1}\end{array}$ & $\begin{array}{c}\text { External } \\
\text { surface } \\
\text { area } \\
\left(\mathrm{m}^{2} \mathbf{g}^{-1}\right)\end{array}$ & $\begin{array}{c}\text { Internal } \\
\text { surface } \\
\text { area } \\
\left(\mathrm{m}^{2} \mathbf{g}^{-1}\right)\end{array}$ & $\begin{array}{c}\text { Internal } \\
\text { pore } \\
\text { volume } \\
\left(\mathrm{ccg}^{-1}\right)^{2}\end{array}$ & $\begin{array}{c}\text { Average } \\
\text { pore } \\
\text { diameter } \\
(\mathrm{nm})^{3}\end{array}$ \\
\hline NaY zeolite & 458.5 & 32.823 & 425.6 & 0.197 & 1.4 \\
Hierarchical MY & 337.7 & 137.730 & 200.0 & 0.093 & 2.2 \\
\hline${ }^{1}$ multipoint BET & & & & & \\
${ }^{2}$ t-method \\
$\begin{array}{l}3 \text { calculated from desorption branch of the related isotherm using } \\
\text { BJH method }\end{array}$
\end{tabular}

constructive" method, no significant change in $\mathrm{Si} / \mathrm{Al}$ ratio and therefore no leakage of $\mathrm{Al}$ or Si has occurred; hence the hydrophilicity of the original zeolite has maintained which is favorite in adsorption of cationic methylene blue dye.

The thermogravimetric analysis (TGA) of the $\mathrm{NaY}$ and MY (Figure 6) show a weight loss at around $100^{\circ} \mathrm{C}$ which is related to losing the adsorbed water. As can be seen both parent and modified zeolite are stable until high temperatures. As the recovery process of the adsorbents will be performed in high temperature (e.g. $500^{\circ} \mathrm{C}$ ), therefore the stability of them in high temperature is favorite.

In Figure 7, the FT-IR spectra of each adsorbent before and after adsorption of MB on their surfaces has been depicted. As can be seen no noticeable alteration is observed. The lack of any shift in the vibration pattern shows that, there are no chemical bonds between the MB and the atoms in the surface of the both adsorbents. As the zeolite framework possesses strong anionic nature [22] and by considering the cationic charge of $\mathrm{MB}$, therefore it can be concluded that, the electrostatic force is in charge of the adsorption process.

\subsection{Adsorption studies}

\subsubsection{The effect of $\mathrm{pH}$ on methylene blue adsorption}

In Figure 8 the effect of $\mathrm{pH}$ of the initial solution on adsorption process has been studied in the range of 2-12 for both microporous $\mathrm{NaY}$ and hierarchical MY zeolites. The $\mathrm{pH}$ based adsorption profile for both of them is almost the same. In more acidic and basic $\mathrm{pH}$, the adsorption capacity is low and between about pH 3-10, the optimum adsorption could be observed. This adsorption behavior is similar to other adsorption processes which already observed [23,24]. The lower adsorption capacity at $\mathrm{pH}$ below 3 can be related to 

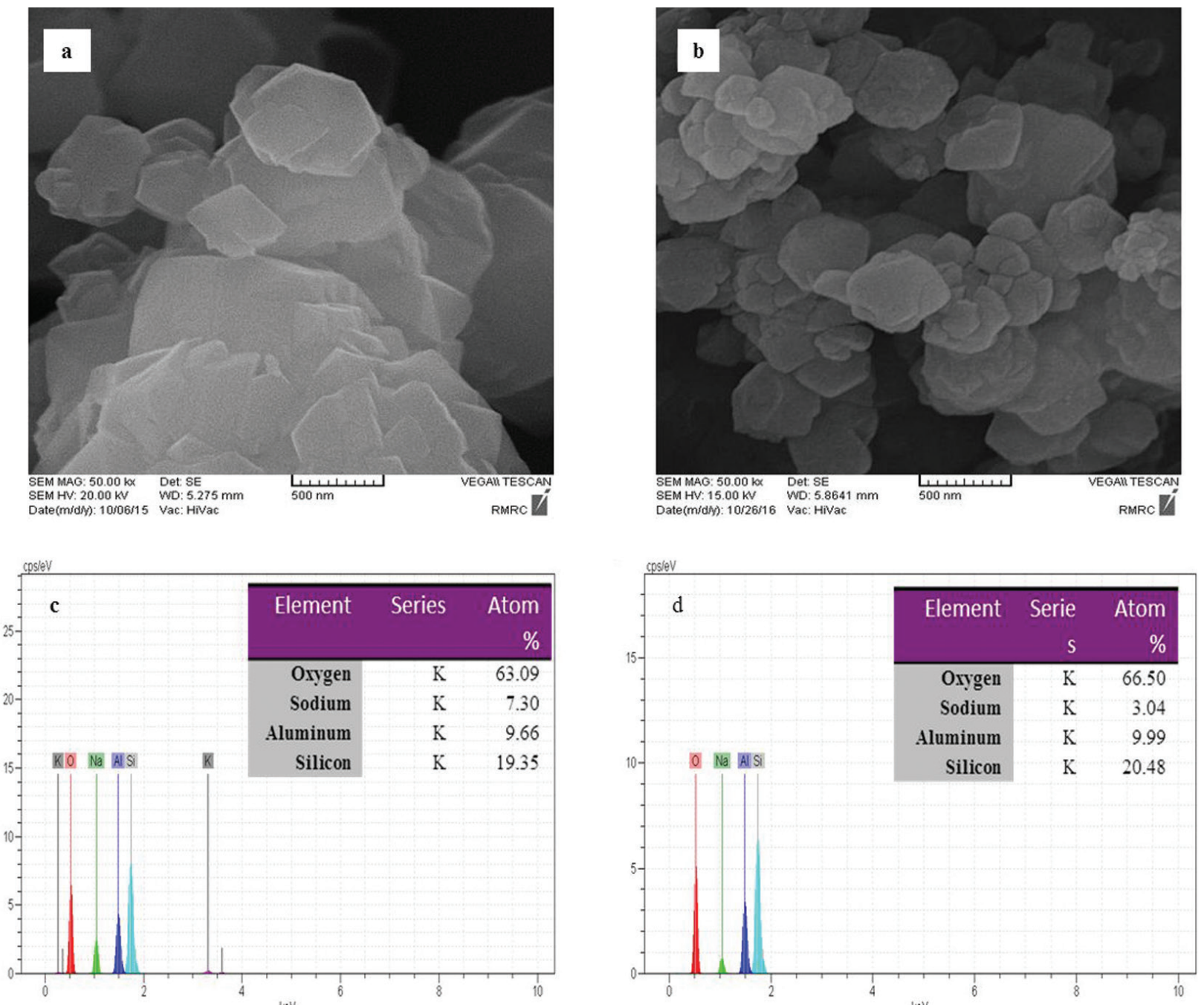

Figure 5: The SEM micrographs of (a) microporous zeolite NaY, (b) hierarchical MY and the EDX plots of (c) microporous NaY, (d) hierarchical MY zeolites; insets show the elemental percentages.

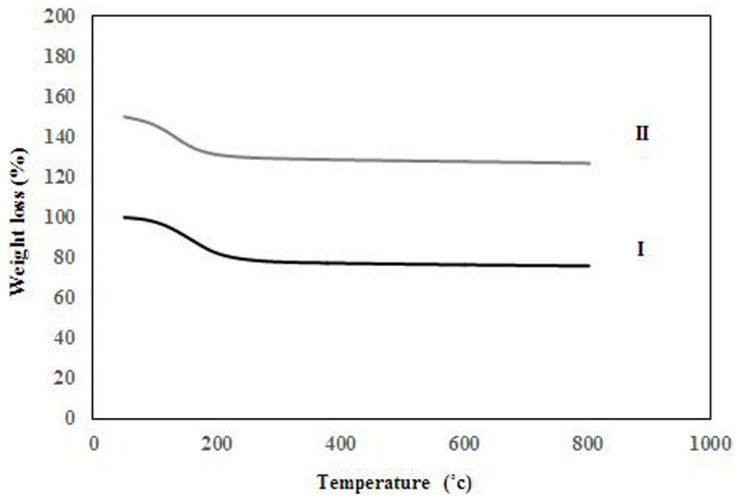

Figure 6: Thermogravimetric analysis (TGA) curve of (I) microporous $\mathrm{NaY}$ and (II) hierarchical MY.

the competition between $\mathrm{H}^{+}$ions with cationic $\mathrm{MB}$ dye on occupying the adsorption sites of zeolites. In our opinion, the decrease in adsorption at higher $\mathrm{pH}$ (more than 11) can be related to the presence of higher amounts of $\mathrm{OH}^{-}$ions which can compete with the zeolite anionic surface as the adsorption sites.

\subsubsection{Adsorption equilibrium studies}

In order to better investigation of the adsorption process, it is essential to study the equilibrium. An adsorption equilibrium usually named adsorption isotherm. It shows how an adsorbate interacts with adsorbent surface and also the amount of tendency of adsorbate to adsorbent will be understood [25]. It can also be used to find the maximum adsorption capacity $\left(\mathrm{q}_{\mathrm{m}}\right)$ of adsorbent. By plotting the solid-phase concentration versus liquidphase concentration at equilibrium, the adsorption isotherm is achieved whereby certain constants will be attained, containing various information about 

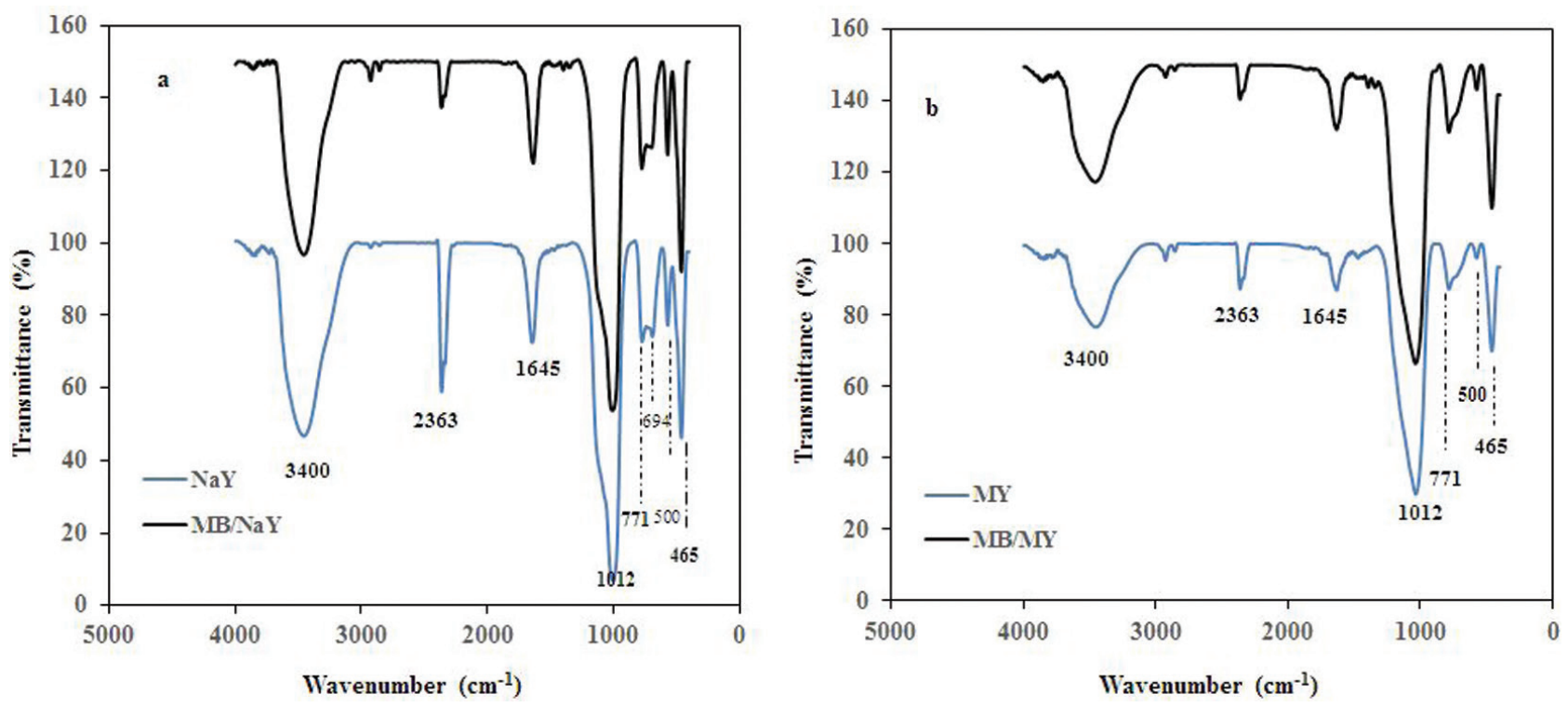

Figure 7: FT-IR spectra of (a) microporous NaY before and after adsorption of methylene blue (MB/NaY) and (b) related FT-IR spectra of hierarchical MY and after adsorption of methylene blue (MB/MY).

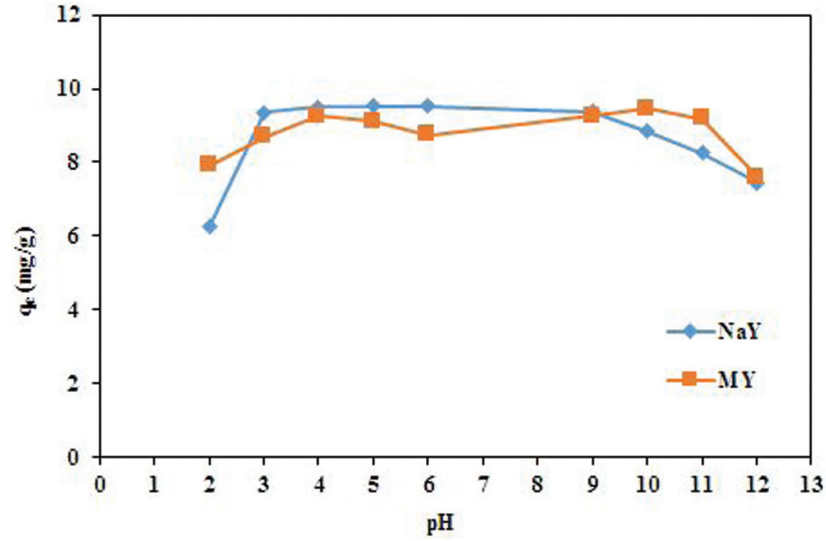

Figure 8: Effect of $\mathrm{pH}$ on equilibrium uptake of $\mathrm{MB}(\mathrm{m}=0.01 \mathrm{~g}$, $\mathrm{V}=0.01 \mathrm{~L}, \mathrm{C}_{0}=10 \mathrm{mg} / \mathrm{L}, \mathrm{T}=20^{\circ} \mathrm{C}$, stirring rate $\left.=250 \mathrm{rpm}\right)$.

the surface properties and affinity of adsorbate to the adsorbent [26]. In order to a comprehensive investigation of the adsorption process, six isotherms (Table 1) has been applied. Figures $9 \mathrm{a}$ and $9 \mathrm{~b}$ show the plots of the related isotherms for MB removal for both adsorbents. Parameters achieved by each isotherm has been inserted in Table 3.

As can be seen, the Langmuir, Redlich-Peterson, Toth, and Temkin possess high correlation coefficient which implies that the adsorption parameters are well matched with the experimental results. The rest isotherms i.e. Freundlich, and Koble-Corrigan also have lower, but acceptable coefficient of determination $\left(\mathrm{R}^{2}\right)$. From the Langmuir isotherm, the maximum adsorption capacity $\left(\mathrm{q}_{\mathrm{m}}\right)$ for parent microporous $\mathrm{NaY}$ is calculated to be
$15.2 \mathrm{mg} / \mathrm{g}$ which was improved to a remarkable amount of $133.1 \mathrm{mg} / \mathrm{g}$ for hierarchical MY.

In Table 4, the values of maximum adsorption capacity $\left(\mathrm{q}_{\mathrm{m}}\right)$ in the removal of $\mathrm{MB}$ for various adsorbents has been inserted. As can be seen the $q_{m}$ for the hierarchical MY has a noticeable amount in comparison with other adsorbents.

The essential characteristics of the Langmuir isotherm is expressed as dimensionless constant separation factor, $\mathrm{R}_{\mathrm{L}}$, which is as follow:

$$
R_{L}=\frac{1}{1+K_{L} C_{0}}
$$

where $\mathrm{C}_{0}$ is the initial concentration and $\mathrm{K}_{\mathrm{L}}$ is the Langmuir isotherm constant. The $\mathrm{R}_{\mathrm{L}}$ values reflect the property of adsorption; $R_{L}>1$ is unfavorable, $R_{L}=1$ is linear, $0<\mathrm{R}_{\mathrm{L}}<1$ : favorable and $\mathrm{R}_{\mathrm{L}}=0$ is irreversible. In Figure 10, $R_{L}$ versus $C_{0}$ has been plotted for both $\mathrm{NaY}$ and MY. It can be seen the values of $R_{L}$ in whole region of initial concentrations are in the range between 0 to 1 for both $\mathrm{NaY}$ and MY which shows the adsorption is a favorable process [27,28]. In addition, it can be seen that by increasing the initial concentration, the adsorption are more favorable.

The $\mathrm{K}_{\mathrm{F}}$ of Freundlich model which is related to adsorption capacity is relatively low for both adsorbents but the value for hierarchical MY indicates noticeable improvement and easier uptake of MB in comparison with microporous NaY zeolite (Table 3). Also, from the Freundlich, the values of $1 / \mathrm{n} 0.16$ for $\mathrm{NaY}$ and 0.22 for 

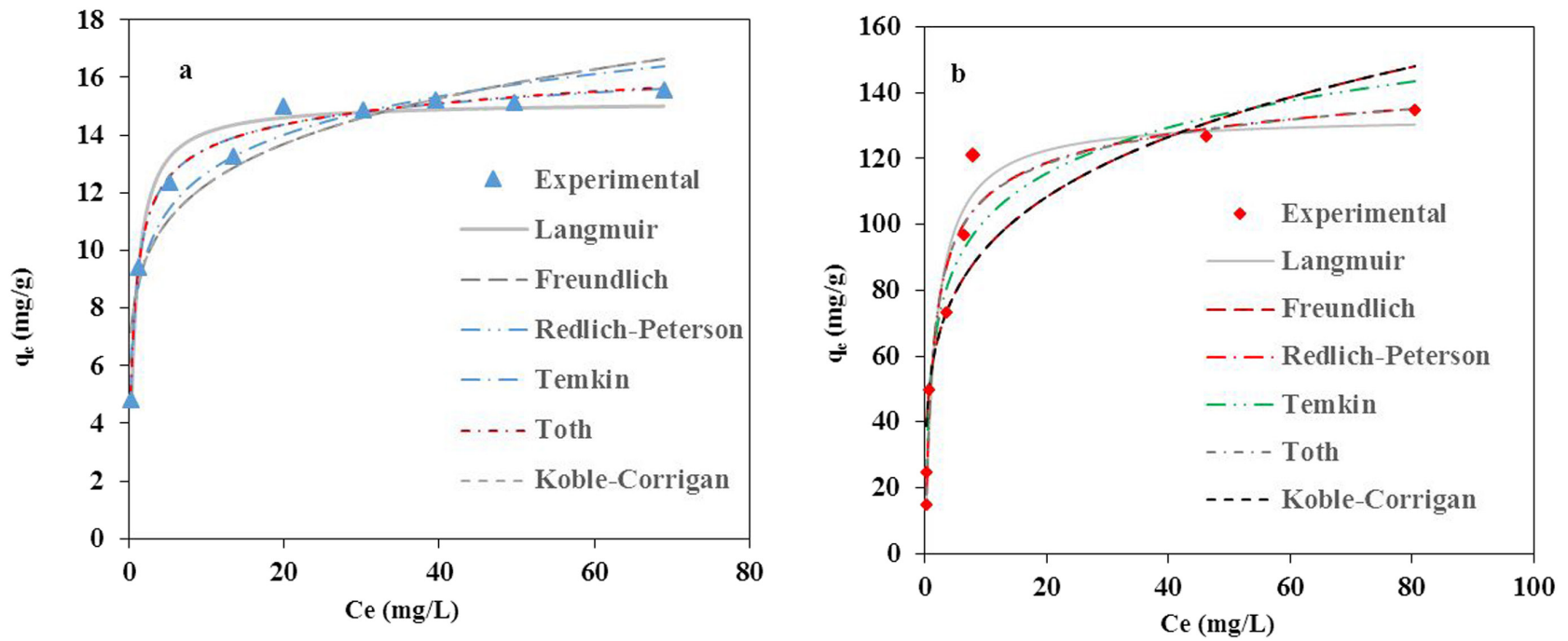

Figure 9: Equilibrium adsorption isotherms of methylene blue on (a) microporous NaY and (b) hierarchical MY.

Table 3: Isotherms parameters values for MB adsorption on microporous $\mathrm{NaY}$ and hierarchical MY.

\begin{tabular}{|c|c|c|c|}
\hline \multirow{2}{*}{ Isotherm } & \multirow{2}{*}{ Parameters } & \multicolumn{2}{|c|}{ Values } \\
\hline & & $\mathrm{NaY}$ & MY \\
\hline \multirow[t]{3}{*}{ Langmuir } & $\mathrm{q}_{\mathrm{m}}(\mathrm{mg} / \mathrm{g})$ & 15.17 & 133.1 \\
\hline & $K_{L}$ & 1.3 & 0.58 \\
\hline & $\mathrm{R}^{2}$ & 0.97 & 0.95 \\
\hline \multirow[t]{3}{*}{ Freundlich } & $\mathrm{K}_{\mathrm{F}}$ & 8.5 & 55.3 \\
\hline & $\mathrm{n}$ & 6.3 & 4.46 \\
\hline & $\mathrm{R}^{2}$ & 0.88 & 0.83 \\
\hline \multirow[t]{4}{*}{ Redlich-peterson } & $A$ & 26.7 & 113.4 \\
\hline & B & 2.11 & 1.1 \\
\hline & $\mathrm{g}$ & 0.95 & 0.94 \\
\hline & $\mathrm{R}^{2}$ & 0.98 & 0.95 \\
\hline \multirow[t]{3}{*}{ Temkin } & $A$ & 8.26 & 55.5 \\
\hline & B & 1.92 & 20.1 \\
\hline & $\mathrm{R}^{2}$ & 0.94 & 0.94 \\
\hline \multirow[t]{4}{*}{ Koble- Corrigan } & $A$ & 2.87 & 13.27 \\
\hline & B & 5.67 & 42.1 \\
\hline & $\mathrm{n}$ & 0.16 & 0.22 \\
\hline & $\mathrm{R}^{2}$ & 0.86 & 0.80 \\
\hline \multirow[t]{4}{*}{ Toth } & $k_{t}$ & 12.38 & 99.5 \\
\hline & $a_{t}$ & 0.47 & 0.92 \\
\hline & $\mathrm{t}$ & 1.06 & 1.07 \\
\hline & $R^{2}$ & 0.98 & 0.95 \\
\hline
\end{tabular}

MY have achieved which are located in the range of $0.1<1 / \mathrm{n}<1$, indicative of a higher adsorbability of MB for both adsorbents [26]. As shown in Table 3, the RedlichPeterson $\mathrm{g}$ parameter is almost 0.95 for both adsorbents which are near the value of 1 and implies that this isotherm is approaching Langmuir isotherm [26]. The Temkin parameters A and B were also listed in Table 3. From microporous NaY to hierarchical MY, the values of A and
Table 4: Comparison between maximum adsorption capacities $\left(\mathrm{q}_{\mathrm{m}}\right)$ of various adsorbents in removal of MB.

\begin{tabular}{|c|c|c|}
\hline Adsorbent & $q_{m}\left(m g ~ g^{-1}\right)$ & Reference \\
\hline Luffa cylindrical fibers & 47.0 & {$[27]$} \\
\hline $\mathrm{NaA}_{\mathrm{mw}}{ }^{1}$ & 64.8 & {$[28]$} \\
\hline Alkaline-treated clinoptilolite & 47.3 & [29] \\
\hline $\mathrm{Au}-\mathrm{NP}-\mathrm{AC}^{2}$ & $104-185$ & {$[30]$} \\
\hline PDA microspheres ${ }^{3}$ & 90.7 & [31] \\
\hline Palm kernel fiber & 95.4 & [32] \\
\hline Kaolin & 45 & {$[23]$} \\
\hline Commercial zeolite & 22 & [23] \\
\hline crosslinked chitosan/bentonite composite & 95.24 & [33] \\
\hline ZnS:Cu-NP-AC ${ }^{4}$ & 106.9 & [34] \\
\hline Fe304 NPs & $89.2-91.9$ & [35] \\
\hline Polyoxometalate & 140.84 & [36] \\
\hline Leaves of Solanum tuberosum & 52.6 & {$[37]$} \\
\hline $\mathrm{Fe} / \mathrm{SCD}-\mathrm{LDH}^{5}$ & $80-100$ & {$[38]$} \\
\hline hierarchical zeolite Y (MY) & 133.1 & This work \\
\hline \multicolumn{3}{|l|}{${ }^{1}$ microwave rapid synthesized $\mathrm{NaA}$ zeolite } \\
\hline \multicolumn{3}{|l|}{${ }^{2}$ gold nanoparticles loaded on activated carbon } \\
\hline \multicolumn{3}{|c|}{${ }^{3}$ Polydopamine } \\
\hline \multicolumn{3}{|c|}{${ }^{4} \mathrm{ZnS}:$ Cu nanoparticles loaded on activated carbon } \\
\hline \multicolumn{3}{|c|}{${ }^{5}$ magnetic Fe304@sulfonated $\beta$-cyclodextrin intercalated LDH } \\
\hline
\end{tabular}
characteristic of the hierarchical MY zeolite [26].

\subsubsection{Kinetic studies}

The kinetic studies are important in order to the industrialization of the adsorption process. The experimental data of kinetic was plotted in Figure 11. The Pseudo- first and second kinetic models, Eq. 2 
and Eq. 3, were used for nonlinear curve fitting. Some publications evaluated the linear and non-linear methods for this purpose and concluded the non-linear methods may be more precise to attain the desired parameters of kinetic [39].

The values of parameters for each model has been inserted in Table 5. The correlation coefficient of Pseudo-second order for both microporous $\mathrm{NaY}$ and hierarchical MY are higher than their values of Pseudofirst order model. Therefore the adsorption kinetic obey Pseudo-second-order model. Several similar results were reported for the adsorption of MB on different adsorbents $[24,27,40,41]$. In addition to data which are achieved by isotherms studies of $\mathrm{NaY}$ and MY, the kinetic achievements

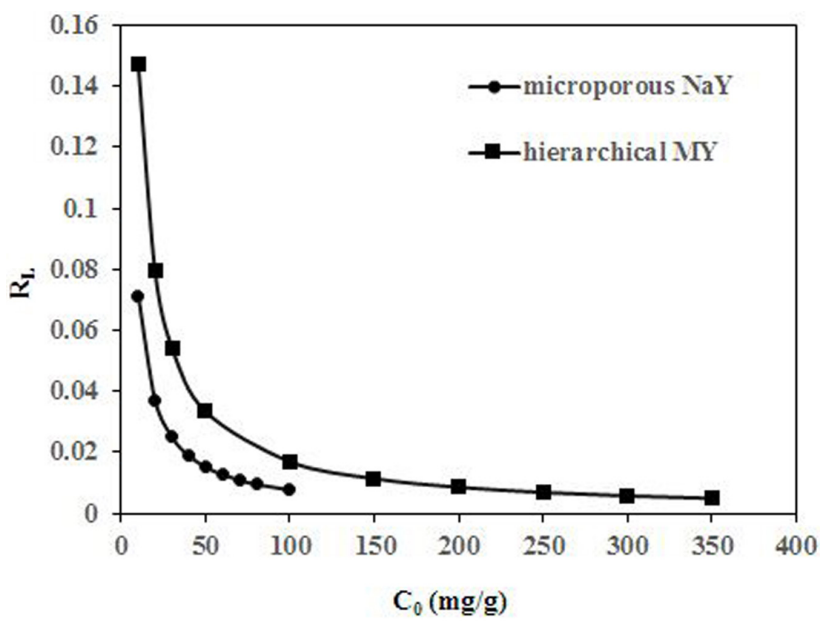

Figure 10: The Langmuir separation factor $\left(R_{1}\right)$ for microporous $\mathrm{NaY}$ and hierarchical MY.

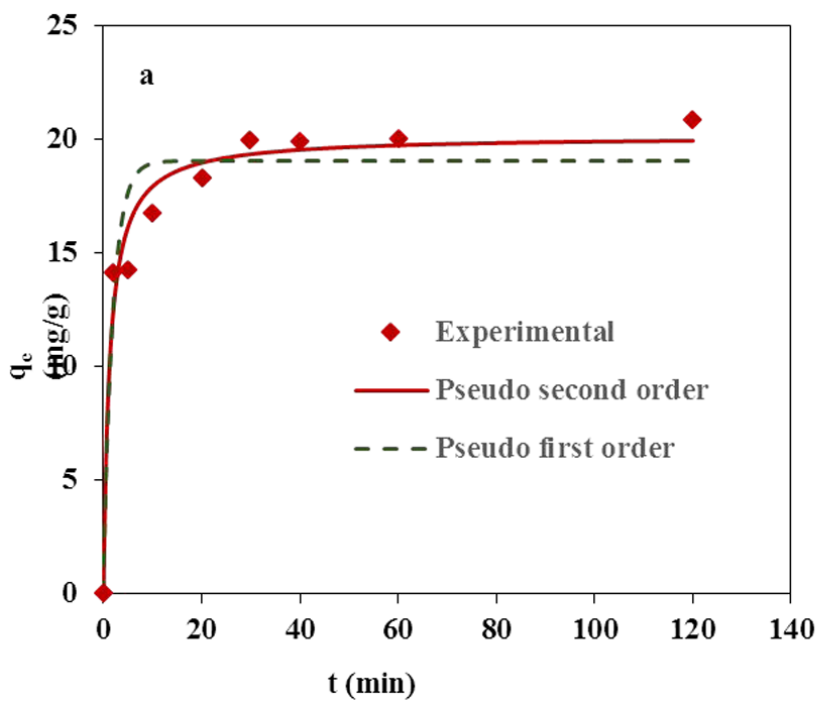

also proved that the mechanism of adsorption process has not altered during the modification process and obeys a similar procedure for both adsorbents.

\subsubsection{Regenerated adsorbents performance}

In order to assess the reusability of the adsorbent and investigation the performance of the modified hierarchical zeolite in successive adsorption process, the MY zeolite was recovered by calcination of MB in a microwave furnace at $500^{\circ} \mathrm{C}$ for $3 \mathrm{~h}$. The removal efficiency versus the frequency of recycling has been plotted in Figure 12. It is seen that after four successive utilization of MY, a slight deterioration in the adsorption performance has occurred. The aggregation and cohesion of the adsorbent after several utilization of adsorbent can lead to reduction in surface area of adsorbent which resulted in decrease in the MB removal after several recovery processes [28].

Table 5: Pseudo-first-order and Pseudo-second-order parameters for the adsorption of MB on NaY and MY.

\begin{tabular}{lccc}
\hline \multirow{2}{*}{ Kinetic model } & \multirow{2}{c}{ Parameters } & \multicolumn{2}{c}{ Values } \\
\cline { 3 - 4 } & & $\mathrm{NaY}$ & $\mathrm{MY}$ \\
\hline Pseudo first order & $\mathrm{q}_{\mathrm{e}}$ & 19.01 & 46.3 \\
& $\mathrm{k}_{1}$ & 0.512 & 0.75 \\
Pseudo second order & $\mathrm{R}^{2}$ & 0.912 & 0.95 \\
& $\mathrm{q}_{\mathrm{e}}$ & 20.13 & 48.08 \\
& $\mathrm{k}_{2}$ & 0.04 & 0.03 \\
& $\mathrm{R}^{2}$ & 0.97 & 0.98 \\
\hline
\end{tabular}

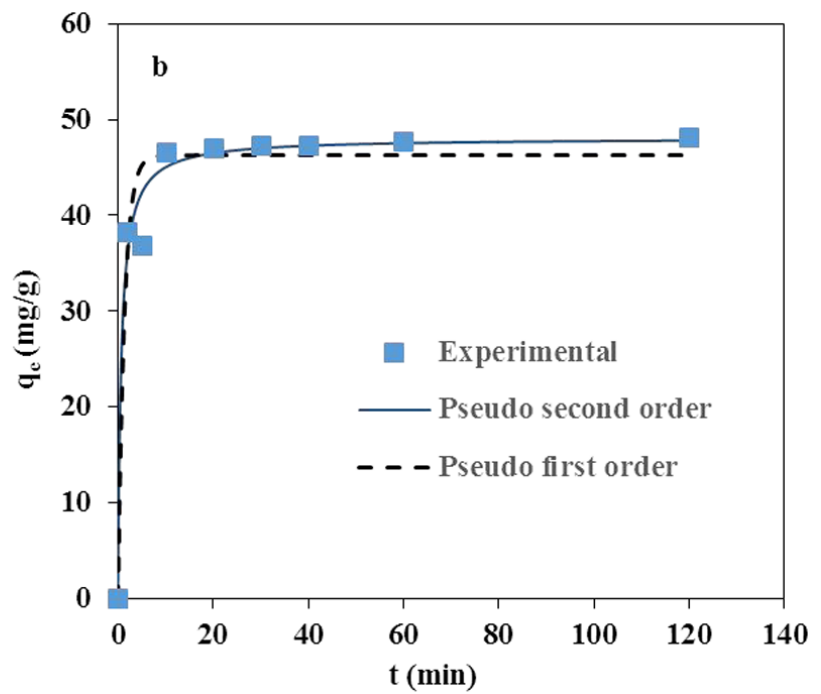

Figure 11: Pseudo-first order and pseudo-second-order kinetic models for (a) microporous NaY and (b) hierarchical MY. 


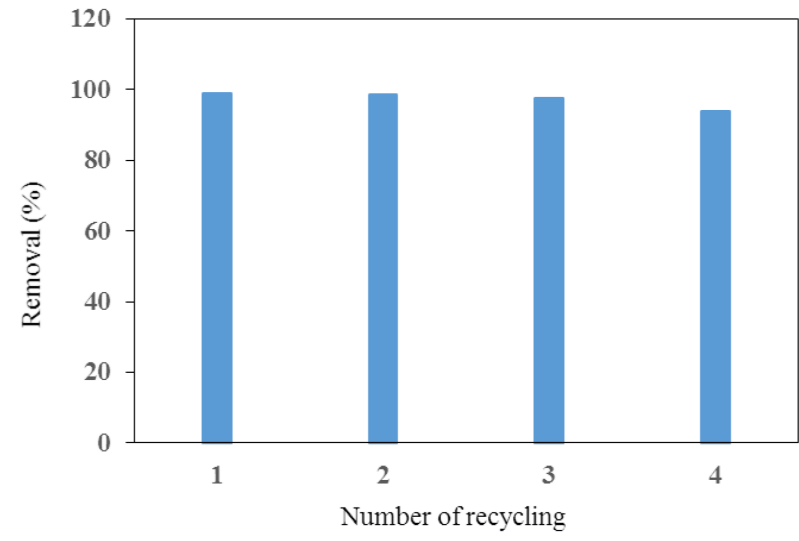

Figure 12: Plot of the reusability test adsorption of MB removal onto hierarchical MY.

\section{Conclusions}

In this study, a zeolite $\mathrm{NaY}$ with a low ratio of $\mathrm{Si} / \mathrm{Al}=2$ was synthesized by silica extracted from rice husk ash. It is higher aluminum content made it a hydrophilic zeolite with a more negative charge which is favorable for the removal of cationic methylene blue dye from the water. After modification of the proposed zeolite to hierarchical one, MY, by a "destructive-constructive" method, the $\mathrm{Si} / \mathrm{Al}$ ratio was maintained and some mesopores were inserted in the zeolite structure. The presence of these mesopores caused a synergistic effect in removal of methylene blue. The proposed MY possessed remarkable adsorption capacity of $133.1 \mathrm{mg} \mathrm{g}^{-1}$ in comparison with the parent $\mathrm{NaY}$ zeolite $\left(15.2 \mathrm{mg} \mathrm{g}^{-1}\right)$ in the removal of the methylene blue dye.

Acknowledgment: The authors thank the University of Mazandaran for financial support.

\section{References}

[1] Visa M., Synthesis and characterization of new zeolite materials obtained from fly ash for heavy metals removal in advanced wastewater treatment. Powder Technol., 2016, 294, 338-347.

[2] Ghaedi M., Heidarpour S., Nasiri S., Sahraie R., Comparison of silver and palladium nanoparticles loaded on activated carbon for efficient removal of Methylene blue: Kinetic and isotherm study of removal process. Powder Technol., 2012, 228, 18-25.

[3] Shahryari Z., Goharrizi A.S., Azadi M., Experimental study of methylene blue adsorption from aqueous solutions onto carbon nano tubes. Int. J. Water Resour. Environ. Eng., 2010, 2, 16-28.
[4] Rafatullah M., Sulaiman O., Hashim R., Ahmad A., Adsorption of methylene blue on low-cost adsorbents: A review. J. Hazard. Mater., 2010, 177, 70-80.

[5] Jin X., Jiang M., Shan X., Pei Z., Chen Z., Adsorption of methylene blue and orange II onto unmodified and surfactant-modified zeolite. J. Colloid Interface Sci., 2008, 328, 243-247.

[6] J. Čejka J., Mintova S., Perspectives of Micro/Mesoporous Composites in Catalysis. Catal. Rev. Sci. Eng., 2007, 49, 457-509.

[7] Ramezani H., Azizi S.N., Hosseini S.R., NaY zeolite as a platform for preparation of $\mathrm{Ag}$ nanoparticles arrays in order to construction of $\mathrm{H}_{2} \mathrm{O}_{2}$ sensor. Sensor. Actuat. B-Chem., 2017, 248, 571-579.

[8] Corma A., From Microporous to Mesoporous Molecular Sieve Materials and Their Use in Catalysis. Chem. Rev., 1997, 97, 2373-2419.

[9] Kulprathipanja S. (Ed.), Zeolites in Industrial Separation and Catalysis. Wiley-VCH, 2010.

[10] Sachse A., Wuttke C., Díaz U., de Souza M.O., Mesoporous Y zeolite through ionic liquid based surfactant templating. Micropor. Mesopor. Mat., 2015, 217, 81-86.

[11] Yan Y., Guo X., Zhang Y., Tang Y., Future of nano-/hierarchical zeolites in catalysis: gaseous phase or liquid phase system. Catal. Sci. Technol., 2015, 5, 772-785.

[12] Taylor P., Van Donk S., Janssen A.H., Bitter J.H., De Jong K.P., Generation, Characterization, and Impact of Mesopores in Zeolite Catalysts. Catal. Rev. Sci. Eng., 2003, 45, 297-319.

[13] Zhang K., Ostraat M.L., Innovations in hierarchical zeolite synthesis. Catal. Today, 2016, 264, 3-15.

[14] Wang S., Dou T., Li Y., Zhang Y., X Li., Yan Z., A novel method for the preparation of MOR/MCM-41 composite molecular sieve. Catal. Commun., 2005, 6, 87-91.

[15] García-Martínez J., Li K., Krishnaiah G., A mesostructured Y zeolite as a superior FCC catalyst - from lab to refinery. Chem. Commun., 2012, 48, 11841-11843.

[16] Shultz J.L., A Simple Method for Production of Pure Silica from Rice Hull Ash. Bioresource Technol., 2000, 73, 257-262.

[17] Chal R., Cacciaguerra T., Donk V., Ge C., Pseudomorphic synthesis of mesoporous zeolite $Y$ crystals. Chem. Commun., 2010, 46, 7840-7842.

[18] García-Martínez J., Johnson M., Valla J., Li K., Ying J.Y., Mesostructured zeolite Y-high hydrothermal stability and superior FCC catalytic performance. Catal. Sci. Technol., 2012, 2, 987-994.

[19] Shahid A., Lopez-Orozco S., Marthala V.R., Hartmann M., Schwieger W., Direct oxidation of benzene to phenol over hierarchical ZSM-5 zeolites prepared by sequential post synthesis modification. Micropor. Mesopor. Mat., 2017, 237, 151-159.

[20] Robson H., Verified synthesis of zeolitic materials (2 ed.). Elsevier, 2001. 
[21] Lowell S., Shields J., Thomas M., Thommes M., Characterization of porous solids and powders: surface area, pore size and density. Kluwer Academic Publishers, 2004.

[22] Yang R.T., Adsorbents: fundamentals and applications. John Wiley \& Sons, 2003.

[23] Rida K., Bouraoui S., Hadnine S., Adsorption of methylene blue from aqueous solution by kaolin and zeolite. Appl. Clay Sci., 2013, 83-84, 99-105.

[24] Hameed B.H., Removal of cationic dye from aqueous solution using jackfruit peel as non-conventional low-cost adsorbent. J. Hazard. Mater., 2009, 162, 344-350.

[25] Gimbert F., Morin-Crini N., Renault F., Badot P.M., Crini G., Adsorption isotherm models for dye removal by cationized starch-based material in a single component system: Error analysis. J. Hazard. Mater., 2008, 157, 34-46.

[26] Han R., Zhang J., Han P., Wang Y., Zhao Z., Tang M., Study of equilibrium, kinetic and thermodynamic parameters about methylene blue adsorption onto natural zeolite. Chem. Eng. J., 2009, 145, 496-504.

[27] Demir H., Top A., Balköse D., Ülkü S., Dye adsorption behavior of Luffa cylindrica fibers. J. Hazard. Mater., 2008, 153, 389-394.

[28] Sapawe N., Jalil A.A., Triwahyono S., Shah M.I.A., Jusoh R., Salleh N.F.M., et al., Cost-effective microwave rapid synthesis of zeolite NaA for removal of methylene blue. Chem. Eng. J., 2013, 229, 388-398.

[29] Akgül M., Karabakan A., Microporous and Mesoporous Materials Promoted dye adsorption performance over desilicated natural zeolite. Micropor. Mesopor. Mat., 2011, 145, 157-164.

[30] Roosta M., Ghaedi M., Daneshfar A., Sahraei R., Asghari A., Optimization of the ultrasonic assisted removal of methylene blue by gold nanoparticles loaded on activated carbon using experimental design methodology. Ultrason. Sonochem., 2014, 21, 242-252.

[31] Fu J., Chen Z., Wang M., Liu S., Zhang J., Zhang J., et al., Adsorption of methylene blue by a high-efficiency adsorbent (polydopamine microspheres): Kinetics, isotherm, thermodynamics and mechanism analysis. Chem. Eng. J., 2015, 259, 53-61.
[32] El-Sayed G.O., Removal of methylene blue and crystal violet from aqueous solutions by palm kernel fiber. Desalination, 2011, 272, 225-232.

[33] Bulut Y., Karaer H., Adsorption of Methylene Blue from Aqueous Solution by Crosslinked Chitosan/Bentonite Composite. J. Dispers. Sci. Technol., 2015, 36, 61-67.

[34] Asfaram A., Ghaedi M., Hajati S., Rezaeinejad M., Goudarzi A., Purkait M.K., Rapid removal of Auramine- 0 and Methylene blue by $\mathrm{ZnS}$ : Cu nanoparticles loaded on activated carbon: A response surface methodology approach. J. Taiwan Inst. Chem. Eng., 2015, 53, 80-91.

[35] Ghaedi M., Hajjati S., Mahmudi Z., Tyagi I., Agarwal S., Maity A., et al., Modeling of competitive ultrasonic assisted removal of the dyes - Methylene blue and Safranin-0 using Fe304nanoparticles. Chem. Eng. J., 2015, 268, 28-37.

[36] Rabbani M., SeghatoleslamiZ.S., Rahimi R., Selective adsorption of organic dye methylene blue by Cs4H2PMo11Fe040 $6 \mathrm{H} 2 \mathrm{O}$ in presence of methyl orange and Rhodamine-B. J. Mol. Struct., 2017, 1146, 113-118.

[37] Gupta N., Kushwaha A.K., Chattopadhyaya M.C., Application of potato (Solanum tuberosum) plant wastes for the removal of methylene blue and malachite green dye from aqueous solution. Arab. J. Chem., 2016, 9, S707-S716.

[38] Hu W., Wu X., Jiao F., Yang W., Zhou Y., Preparation and characterization of magnetic $\mathrm{Fe}_{3} \mathrm{O}_{4} @$ sulfonated $\beta$-cyclodextrin intercalated layered double hydroxides for methylene blue removal. Desalin. Water Treat., 2016, 57, 25830-25841.

[39] Raghunadh Acharyulu S., Gomathi T., Sudha P.N., Physico-chemical characterization of cross linked chitosan-polyacrylonitrile polymer blends. Der Pharm. Lett., 2013, 5, 354-363.

[40] Ponnusami V., Vikram S., Srivastava S.N., Guava (Psidium guajava) leaf powder: Novel adsorbent for removal of methylene blue from aqueous solutions. J. Hazard. Mater., 2008, 152, 276-286.

[41] Özer A., Dursun G., Removal of methylene blue from aqueous solution by dehydrated wheat bran carbon. J. Hazard. Mater., 2007, 146, 262-269. 